TITLE:

\title{
Thermally stimulated current studies on neutron irradiation induced defects in GaN
}

$\operatorname{AUTHOR}(S):$

Kuriyama, K; Ooi, M; Onoue, A; Kushida, K; Okada, $\mathrm{M} ; \mathrm{Xu}, \mathrm{Q}$

\section{CITATION:}

Kuriyama, K...[et al]. Thermally stimulated current studies on neutron irradiation induced defects in GaN. APPLIED PHYSICS LETTERS 2006, 88(13): 132109.

ISSUE DATE:

2006-03-27

URL:

http://hdl.handle.net/2433/39677

\section{RIGHT:}

Copyright 2006 American Institute of Physics. This article may be downloaded for personal use only. Any other use requires prior permission of the author and the American Institute of Physics. 


\title{
Thermally stimulated current studies on neutron irradiation induced defects in GaN
}

\author{
K. Kuriyama, ${ }^{\text {a) }}$ M. Ooi, and A. Onoue \\ College of Engineering and Research Center of Ion Beam Technology, Hosei University, Koganei, \\ Tokyo 184-8584, Japan \\ K. Kushida \\ Department of Arts and Sciences, Osaka Kyouiku University, Kashiwara, Osaka 582-8582, Japan \\ M. Okada and Q. Xu \\ Research Reactor Institute, Kyoto University, Kumatori, Osaka 540-0494, Japan
}

(Received 26 November 2005; accepted 15 February 2006; published online 28 March 2006)

\begin{abstract}
The evaluation of the neutron irradiation induced defects in $\mathrm{GaN}$ is studied using a thermally stimulated current (TSC) method with excitation above (below) the energy band gap using ultraviolet (blue, green, red, and infrared) emitting diodes. Annealing at $1000{ }^{\circ} \mathrm{C}$, a broad TSC spectrum for excitation by the ultraviolet light is resolved by five traps, $P_{1}$ (ionization energy is $200 \mathrm{meV}), P_{2}(270 \mathrm{meV}), P_{3}(380 \mathrm{meV}), P_{4}(490 \mathrm{meV})$, and $P_{5}(595 \mathrm{meV})$. Infrared illumination shows a remarkable reduction in TSC for the $P_{2}$ and $P_{3}$ traps, indicating the photoquenching behavior. The possible origins of the observed five traps are discussed. () 2006 American Institute of Physics. [DOI: 10.1063/1.2190446]
\end{abstract}

Gallium nitride exhibits unique electrical, optical, and thermal properties, which make it a promising material for optoelectronic and high-power devices. For space-based applications, these devices will have to operate in a radiation environment. In particular, the device operation will be affected by deep level defects. Neutron irradiation is a useful method for the controlled impurity doping ${ }^{1}$ by nuclear reactions and homogeneous defect production ${ }^{1}$ because of the strong penetration into materials of neutron. Several experiments using deep-level-transient spectroscopy (DLTS), ${ }^{2-5}$ isothermal capacitance transient spectroscopy (ICTS), ${ }^{4}$ photoemission capacitance transient spectroscopy, ${ }^{3}$ capacitancevoltage $(C-V)$ measurement, ${ }^{4}$ and thermally stimulated current (TSC) spectroscopy ${ }^{5-7}$ have been performed to confirm the theoretical calculations of the native defects. In particular, the TSC method is favorable for the high resistive neutron irradiated materials because the TSC technique is applied without the fabrication of Schottky contacts or $p-n$ junctions.

In this letter, we report five traps in neutron irradiated GaN by a TSC method with excitation above the energy band gap using an ultraviolet emitting diode. Photoquenching behavior of $P_{2}$ and $P_{3}$ traps due to the infrared illumination is also reported. Possible candidates of these traps are discussed.

A 5- $\mu$ m-thick unintentionally doped $n$-type $\mathrm{GaN}$ film was grown on a thin $(400 \AA)$ AlN buffer layer deposited on a sapphire substrate by metal-organic vapor-phase epitaxy (MOVPE). The unirradiated samples showed the resistivity of $10^{5}-10^{6} \Omega \mathrm{cm}$. The resistivity of the samples irradiated using a neutron irradiation field ${ }^{8}$ as described later decreased to $10^{4} \Omega \mathrm{cm}$ by the $1000{ }^{\circ} \mathrm{C}$ annealing. In order to investigate the residual deep defects after the $1000{ }^{\circ} \mathrm{C}$ annealing, the TSC method was used in the present study. $\mathrm{Al}$ and $\mathrm{Au}$ alloy electrodes were fabricated on the four corners of

\footnotetext{
${ }^{a)}$ Electronic mail: kuri@ionbeam.hosei.ac.jp
}

samples of $5 \times 5 \mathrm{~cm}^{2}$ in area. The bias voltage of $20 \mathrm{~V}$ was applied on the electrodes for the TSC measurements using a Van der Pauw technique. Samples were cooled down to $85 \mathrm{~K}$ and initialized by illumination for 20 min with an ultraviolet emitting diode [a peak wavelength of $\lambda=365 \mathrm{~nm}$ with a full width at half maximum (FWHM) of $10 \mathrm{~nm}$ at $300 \mathrm{~K}$ ] for the excitation above the energy band gap. In comparison with the illumination above the energy gap, TSC measurements for the excitation below the band gap were also performed using blue $(\lambda=475 \mathrm{~nm}, \mathrm{FWHM}=25 \mathrm{~nm})$, green $(530 \mathrm{~nm}$, $35 \mathrm{~nm})$, red $(644 \mathrm{~nm}, 18 \mathrm{~nm})$, and infrared $(950 \mathrm{~nm}, 50 \mathrm{~nm})$ emitting diodes.

Neutron transmutation doping (NTD) was performed using the center of the core in the Kyoto University Reactor (KUR). ${ }^{8}$ Samples were irradiated with fast (fluence equals $\left.1.05 \times 10^{19} \mathrm{~cm}^{-2}\right)$ and thermal neutrons $\left(2.20 \times 10^{19} \mathrm{~cm}^{-2}\right)$ at fluxes of $3.90 \times 10^{13}$ and $8.15 \times 10^{13} \mathrm{~cm}^{-2} \mathrm{~s}^{-1}$ for each neutron. On the other hand, the neutron irradiation using the Material Controlled Irradiation Facility ${ }^{9}$ (MCIF) was performed under $400{ }^{\circ} \mathrm{C}$ with the fluence of $1.62 \times 10^{19} \mathrm{~cm}^{-2}$ for thermal neutrons and $4.59 \times 10^{18} \mathrm{~cm}^{-2}$ for fast ones, and the resistivity of the MCIF samples drastically decreased from $10^{5}-10^{6}$ to $1-10 \Omega \mathrm{cm}$ after the thermal annealing at $1100{ }^{\circ} \mathrm{C}$, showing a significant NTD effect. However, TSC spectra resulting from lattice defects were not observed for the MCIF irradiated samples because of the large amount of electrons and/or holes in the conduction and/or valence bands. Accordingly, the conventional irradiation ${ }^{8}$ with the large fluence of fast neutrons decreases NTD efficiency due to the large amount of the introduced defects. Furthermore, after the neutron transmutation reactions,${ }^{10}$ the transmuted atoms are usually not in their original positions but displaced into interstitial positions due to the recoil produced by the $\gamma$ and $\beta$ particles in the nuclear reactions.

Figure 1 shows the photoluminescence (PL) spectra for the $1000{ }^{\circ} \mathrm{C}$ annealed NTD GaN, together with an unirradiated GaN. PL spectra were taken at $20 \mathrm{~K}$ using the $325 \mathrm{~nm}$ line of a $35 \mathrm{~mW} \mathrm{He}-\mathrm{Cd}$ laser. Before irradiation, the PL 


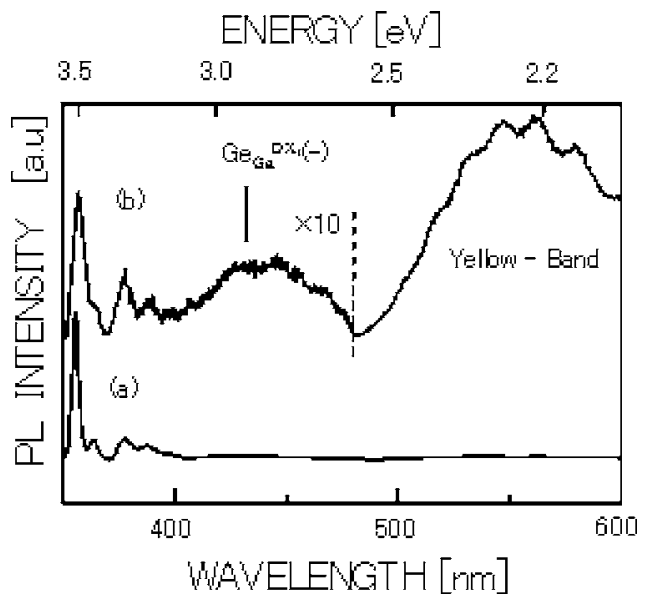

FIG. 1. Photoluminescence spectra at $20 \mathrm{~K}$ taken from unirradiated (a) and $1000{ }^{\circ} \mathrm{C}$ annealed NTD (b) GaN used for TSC measurements.

spectrum [Fig. 1(a)] is dominated by the donor-bound exciton recombination at $3.490 \mathrm{eV}$. A broad PL emission with maximum position at $\sim 3.3 \mathrm{eV}$ was also observed, which would be related to a shallow donor-accepter pair. ${ }^{11}$ In asirradiated samples, PL emissions were not observed at all, indicating that the dominant recombination process is a nonradiative one due to the irradiation induced damages. In NTD GaN annealed at $1000{ }^{\circ} \mathrm{C}$ for $60 \mathrm{~min}$ [Fig. 1(b)], two broad emissions appear at $2.91 \mathrm{eV}$ [blue luminescence (BL)] and $2.25 \mathrm{eV}$ [yellow luminescence (YL)]. Although it is known that the $\mathrm{BL}$ observed in undoped $\mathrm{GaN}$ is attributed to a $\mathrm{V}_{\mathrm{Ga}}$ complex such as $\mathrm{V}_{\mathrm{Ga}} \mathrm{O}_{\mathrm{N}}$ and $\mathrm{V}_{\mathrm{Ga}} \mathrm{H}_{n}$, ${ }^{11}$ we propose that the former emission ${ }^{10}$ has been related to a $D X_{1}$ state ${ }^{12,13}$ of the negatively charged $\mathrm{Ge}_{\mathrm{Ga}}\left[\mathrm{Ge}_{\mathrm{Ga}}{ }^{D X}(-)\right]$ introduced by the neutron irradiation. The transformation of the impurity to a $D X$ configuration is commonly accompanied by a capture of a second electron by the donor. The YL has also been assigned to a complex defect between the transmuted Ge donor and $\mathrm{V}_{\mathrm{Ga}}$ acceptor. ${ }^{10}$

Figure 2 shows the TSC spectra for the $1000{ }^{\circ} \mathrm{C}$ annealed NTD GaN taken after illumination with the ultraviolet light, together with an unirradiated GaN. The TSC spectra for the samples annealed below $800{ }^{\circ} \mathrm{C}$ were not observed at all. In unirradiated samples, four peaks were observed at a peak temperature $T_{m}=200 \mathrm{~K}$ (peak $\left.P_{01}\right), 225 \mathrm{~K}\left(P_{02}\right), 250 \mathrm{~K}$ $\left(P_{03}\right)$, and $280 \mathrm{~K}\left(P_{04}\right)$. The peak positions of $P_{02}$ and $P_{03}$ are similar to the $B_{x}$ and $C_{1}$ traps observed in unintentionally doped semi-insulating GaN reported by Fang et al., ${ }^{5}$ suggesting the same origins. But the thermally stimulated current of unirradiated samples is two orders of magnitude lower than that in NTD GaN. Therefore, the TSC peaks in NTD GaN would additionally result from the neutron irradiation. In neutron irradiated samples, a broad TSC spectrum was observed at a temperature ranging from 100 to $290 \mathrm{~K}$ for excitation by the ultraviolet light. A software, the curve fitting toolbox of MATLAB (The Math Works, Inc.), was used to resolve the broad spectrum to optimum Gaussian curves. As a result, the broad spectrum is resolved to five traps, $P_{1}$ $\left(T_{m}=115 \mathrm{~K}\right), P_{2}(145 \mathrm{~K}), P_{3}(190 \mathrm{~K}), P_{4}(235 \mathrm{~K})$, and $P_{5}$ $(270 \mathrm{~K})$, as shown in Fig. 2. According to the approximate relationship ${ }^{14} E_{i} \approx k T_{m} \ln \left(T_{m}{ }^{4} / \beta\right)$, where $E_{i}$ is the ionization energy (trap depth), $k$ is Boltzmann's constant, $T_{m}$ is the TSC peak temperature, and $\beta$ is the heating rate for the thermal scan (a typical value used here is $0.14 \mathrm{~K} \mathrm{~s}^{-1}$ ), the ionization Downloaded 30 May 2007 to 130.54110 .22 Redistribution subject

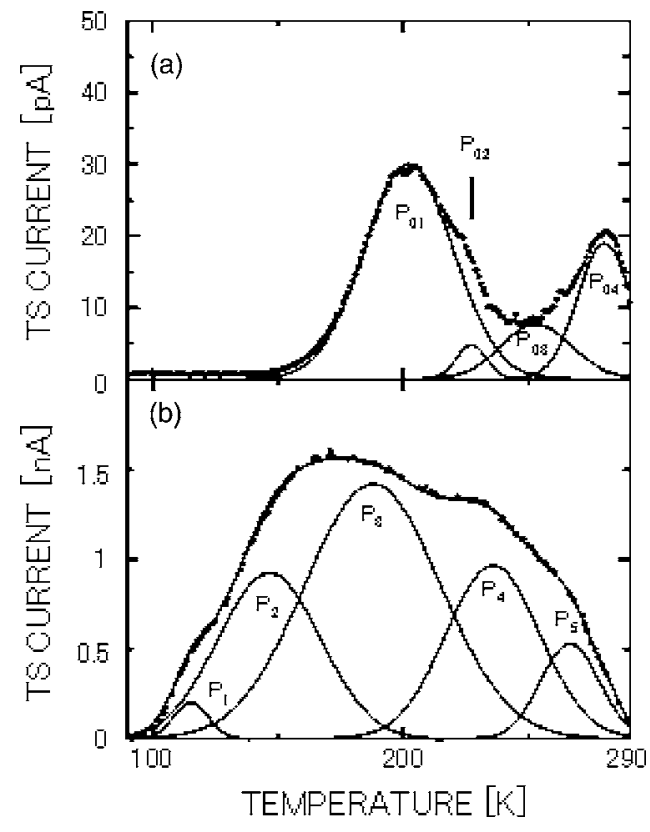

FIG. 2. TSC spectra taken from unirradiated (a) and $1000{ }^{\circ} \mathrm{C}$ annealed NTD (b) GaN for the excitation due to ultraviolet light. The spectrum of the NTD $\mathrm{GaN}$ is resolved by five traps.

energies, $E_{i}\left(P_{1}\right)=200, E_{i}\left(P_{2}\right)=270, E_{i}\left(P_{3}\right)=380, E_{i}\left(P_{4}\right)$ $=490$, and $E_{i}\left(P_{5}\right)=595 \mathrm{meV}$, for these traps were calculated. $E_{i}$ values estimated by the present TSC study contain an uncertainty of $\pm 20 \mathrm{meV}$. Figure 3 shows the TSC spectra in the same GaN sample taken after illumination below the band gap. Thermally stimulated current, peak temperature, and ionization energy for each trap are summarized in Table I for neutron irradiated GaN, together with those of unirradiated GaN. The $P_{1}$ trap is responsive to the excitations by blue and green lights, whereas $P_{1}, P_{4}$, and $P_{5}$ traps are weakly responsive to the excitation by red and infrared lights. An interesting feature is a remarkable reduction in thermally stimulated current of $P_{2}$ and $P_{3}$ traps for the $950 \mathrm{~nm}$ illumination, suggesting the photoquenching behavior of these traps. Although TSC method usually cannot distinguish the sign of a trap (an electron or a hole trap), possible origins of the observed traps are discussed below.

The $P_{1}$ trap is close to a $E$ trap $(180 \mathrm{meV})$ observed in $1 \mathrm{MeV}$ electron irradiated $\mathrm{GaN}^{2}$ The response to the blue and green light emissions indicates that the electrons fill to $P_{1}$ trap via the conduction band from the YL band. Although the origin of the $E$ trap has not been clearly identified, this

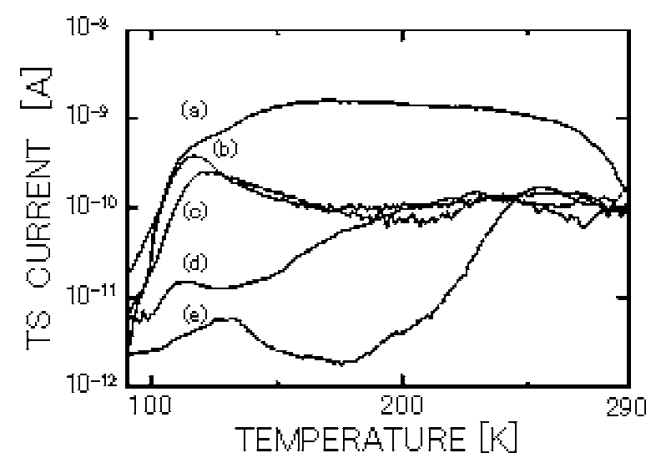

FIG. 3. Logarithm plots of TSC spectra of $1000{ }^{\circ} \mathrm{C}$ annealed NTD GaN; (a), (b), (c), (d), and (e) represent the spectra for ultraviolet, blue, green, red, and infrared illuminations, respectively.

o AIP license or copyright, see http://apl.aip.org/apl/copyright.jsp 
TABLE I. TSC data for the unirradiated and neutron irradiated GaN.

\begin{tabular}{llrcr}
\hline \hline & & \multicolumn{2}{c}{ Peaks } & \\
\cline { 3 - 4 } Sample & Traps & $\begin{array}{c}\text { Current } \\
(\mathrm{pA})\end{array}$ & $\begin{array}{c}\text { Temperature } \\
(\mathrm{K})\end{array}$ & $\begin{array}{c}\text { Ionization } \\
\text { energy } \\
(\mathrm{meV})\end{array}$ \\
\hline Unirradited & $P_{01}$ & 30 & 200 & 400 \\
& $P_{02}$ & 5 & 225 & 450 \\
& $P_{03}$ & 10 & 250 & 519 \\
Neutron & $P_{04}$ & 21 & 280 & 630 \\
irradiated & $P_{1}$ & 200 & 115 & 200 \\
$\left(1000{ }^{\circ} \mathrm{C}\right.$ & $P_{2}$ & 900 & 145 & 270 \\
annealed) & $P_{3}$ & 1400 & 190 & 380 \\
& $P_{4}$ & 950 & 235 & 490 \\
& $P_{5}$ & 500 & 270 & 595 \\
\hline
\end{tabular}

defect center is believed to be a defect complex involving nitrogen vacancy $\left(\mathrm{V}_{\mathrm{N}}\right){ }^{15}$ On the other hand, a possible origin of the $T_{5}$ trap $(530 \mathrm{meV})$ observed in TSC measurements using unirradiated $\mathrm{GaN}$ has been proposed to $\mathrm{V}_{\mathrm{N}}$-related defects. ${ }^{6}$ We assign the $P_{1}$ trap to the defect complex involving $\mathrm{V}_{\mathrm{N}}$ at this time, since the trap with energies between 180-200 meV would be effectively produced by neutron irradiation rather than electron irradiation.

The quenching behavior of $P_{2}$ and $P_{3}$ traps is similar to that of $T_{3}$ trap $(320 \pm 40 \mathrm{meV})$ (Ref. 7) induced by the excitation using a $690 \mathrm{~nm}$ laser diode. In the present study, however, $P_{2}$ and $P_{3}$ traps do not show a remarkable reduction in thermally stimulated current for the illumination of the $644 \mathrm{~nm}$ light-emitting diode (LED). Therefore, the photoquenching behavior observed here may attribute to a different quenching mechanism and/or a different species of defect in comparison with $T_{3}$ trap. The activation energies of $P_{2}$ and $P_{3}$ traps are close to the energy levels of the calculated neutral Ga vacancy. ${ }^{13}$ However, since lattice relaxation accompanied by $\mathrm{V}_{\mathrm{Ga}}$ has been predicted ${ }^{16}$ to be negligible, the photoquenching behavior of $P_{2}$ and $P_{3}$ traps for the infrared illumination may be attributed to the defect complexes involving $\mathrm{V}_{\mathrm{Ga}}$ rather than the isolated neutral $\mathrm{V}_{\mathrm{Ga}}$.

The energy level of the $P_{4}$ trap is close to an energy level of $D X$-like center, which introduces a singlet, almost degenerate with the valence band top, and a second singlet about $0.5 \mathrm{eV}$ below the bottom of the conduction band, ${ }^{12}$ as observed in photoluminescence measurements. Therefore, this trap is likely to be related to $D X$-like center of $\mathrm{Ge}_{\mathrm{Ga}}$.

The energy level of the $P_{5}$ trap is close to a defect level labeled $D_{2}$ with an activation energy ${ }^{17}$ of $E_{D_{2}}=598 \pm 20 \mathrm{meV}$ in $270-\mathrm{keV} \mathrm{N}^{2+}$ implanted and annealed MOVPE grown GaN. This defect is coincident with a deep level with an activation energy ${ }^{4}$ of $\Delta E 2=580 \pm 17 \mathrm{meV}$ in unintentionally doped $n$-type metal-organic chemical-vapor deposition (MOCVD) grown GaN. This deep level is believed to be the $\mathrm{N}_{\mathrm{Ga}}{ }^{17}$ In a theoretical calculation ${ }^{18}$ using a model tight-binding Hamiltonian, neutral $\mathrm{N}_{\mathrm{Ga}}$ in $\mathrm{GaN}$ is a deep-hole trap located at about $500 \mathrm{meV}$ below the conduc- tion band edge, while in the computations ${ }^{12}$ using $a b$ initio molecular dynamics, $\mathrm{N}_{\mathrm{Ga}}$ introduces a doubly occupied singlet at $E_{V}+0.4 \mathrm{eV}$ and an empty doublet at $E_{C}-0.2 \mathrm{eV}$. This empty doublet cannot be occupied even by one electron, due to the large value of the electron-electron repulsion parameter for this level. ${ }^{12}$ Although there is a discrepancy between the theoretical calculations, according to the experimental study ${ }^{17}$ we assigned the $P_{5}$ trap to $\mathrm{N}_{\mathrm{Ga}}$ at this time.

In summary, we have studied the deep levels in neutron irradiated $\mathrm{GaN}$ by TSC measurements. Five traps, $P_{1}-P_{5}$, were observed. $P_{2}$ and $P_{3}$ traps showed the remarkable reduction of thermally stimulated current by the illumination with infrared light, suggesting the photoquenching behavior of these traps. Most probable candidates of these five traps were also proposed.

Part of this work was carried out under the Visiting Researchers of Kyoto University Research Reactor Institute (KURRI).

${ }^{1}$ M. Satoh, H. Kawahara, K. Kuriyama, T. Kawakubo, K. Yoneda, and I. Kimura, J. Appl. Phys. 63, 1099 (1988); M. Satoh and K. Kuriyama, Phys. Rev. B 40, 3473 (1989); M. Satoh, K. Kuriyama, and T. Kawakubo, J. Appl. Phys. 67, 3542 (1990).

${ }^{2}$ D. C. Look, D. C. Reynolds, J. W. Hemsky, J. R. Sizelove, R. L. Jones, and R. J. Molnar, Phys. Rev. Lett. 79, 2273 (1997); Z.-Q. Fang, J. W. Hemsky, D. C. Look, and M. P. Mack, Appl. Phys. Lett. 72, 448 (1998). ${ }^{3}$ W. Götz, N. M. Johnson, H. Amino, and I. Akasaki, Appl. Phys. Lett. 65, 463 (1994).

${ }^{4}$ P. Hacke, T. Detchprohm, K. Hiramatsu, N. Sawaki, K. Tadatomo, and K. Miyake, J. Appl. Phys. 76, 304 (1994).

${ }^{5}$ D. C. Look, Z.-Q. Fang, W. Kim, Ö. Aktas, A. Botchkarev, A. Salvador, and H. Morkoç, Appl. Phys. Lett. 68, 3775 (1996); U. V. Desnica, M. Pavlović, Z.-Q. Fang, and D. C. Look, J. Appl. Phys. 92, 4126 (2002); Z.-Q. Fang, B. B. Claflin, D. C. Look, T. H. Myers, D. D. Koleske, A. E. Wickenden, and R. L. Henry, Mater. Res. Soc. Symp. Proc. 743, 749 (2003).

${ }^{6}$ Z. C. Huang, J. C. Chen, and D. Wickende, J. Cryst. Growth 170, 326 (1997).

${ }^{7}$ H. Witte, A. Krtschil, M. Lisker, E. Schrenk, J. Christen, A. Krost, B. Kuhn, and F. Scholz, Appl. Phys. Lett. 82, 4083 (2003); H. Witte, E. Schrenk, K. Flügge, A. Krost, J. Christen, B. Kuhn, and F. Sholz, Phys. Rev. B 71, 125213 (2005).

${ }^{8}$ K. Kuriyama, K. Tomizawa, S. Uematsu, and H. Takahashi, Appl. Phys. Lett. 65, 746 (1994); K. Kuriyama, J. Takahashi, M. Okada, and M. Uchida, Solid State Commun. 126, 309 (2003).

${ }^{9}$ T. Yoshiie, Y. Hayashi, S. Yanagita, Q. Xu, Y. Satoh, H. Tsujimoto, T. Kozuka, K. Kamae, K. Mishima, S. Shiroya, K. Kobayashi, M. Utsuro, and Y. Fujita, Nucl. Instrum. Methods Phys. Res. A 498, 522 (2003).

${ }^{10}$ K. Kuriyama, T. Tokumasu, J. Takahashi, H. Kondo, and M. Okada, Appl. Phys. Lett. 80, 3328 (2002).

${ }^{11}$ M. A. Reshchikov and H. Morkoc, J. Appl. Phys. 97, 061301 (2005).

${ }^{12}$ P. Bogusławski, E. L. Briggs, and J. Bernholc, Phys. Rev. B 51, 17255 (1995); P. Bogusławski and J. Bernholc, ibid. 56, 9496 (1997).

${ }^{13}$ J. Neugebauer and C. G. Van de Walle, Phys. Rev. B 50, 8067 (1994).

${ }^{14}$ D. C. Look, Semicond. Semimetals 19, 75 (1983).

${ }^{15}$ Z.-Q. Fang, D. C. Look, W. Kim, and H. Morkoc, MRS Internet J. Nitride Semicond. Res. 5S1, W11.84 (2000).

${ }^{16}$ I. Gorczyca, A. Svane, and N. E. Christensen, Phys. Rev. B 60, 8147 (1999).

${ }^{17}$ D. Haase, M. Schmid, W. Kürner, A. Dörnen, V. Härle, F. Scholz, M. Burkard, and H. Schweizer, Appl. Phys. Lett. 69, 2525 (1996).

${ }^{18}$ D. W. Jenkins and J. D. Dow, Phys. Rev. B 39, 3317 (1989). 